\title{
Instituições de Saúde e a Morte. Do Interdito à Comunicação
}

Health Institutions and Death. From Interdict to Communication

Instituciones de Salud y la Muerte. De lo Prohibido a la Comunicación

Maria Júlia Kovács Instituto de

Psicologia da USP
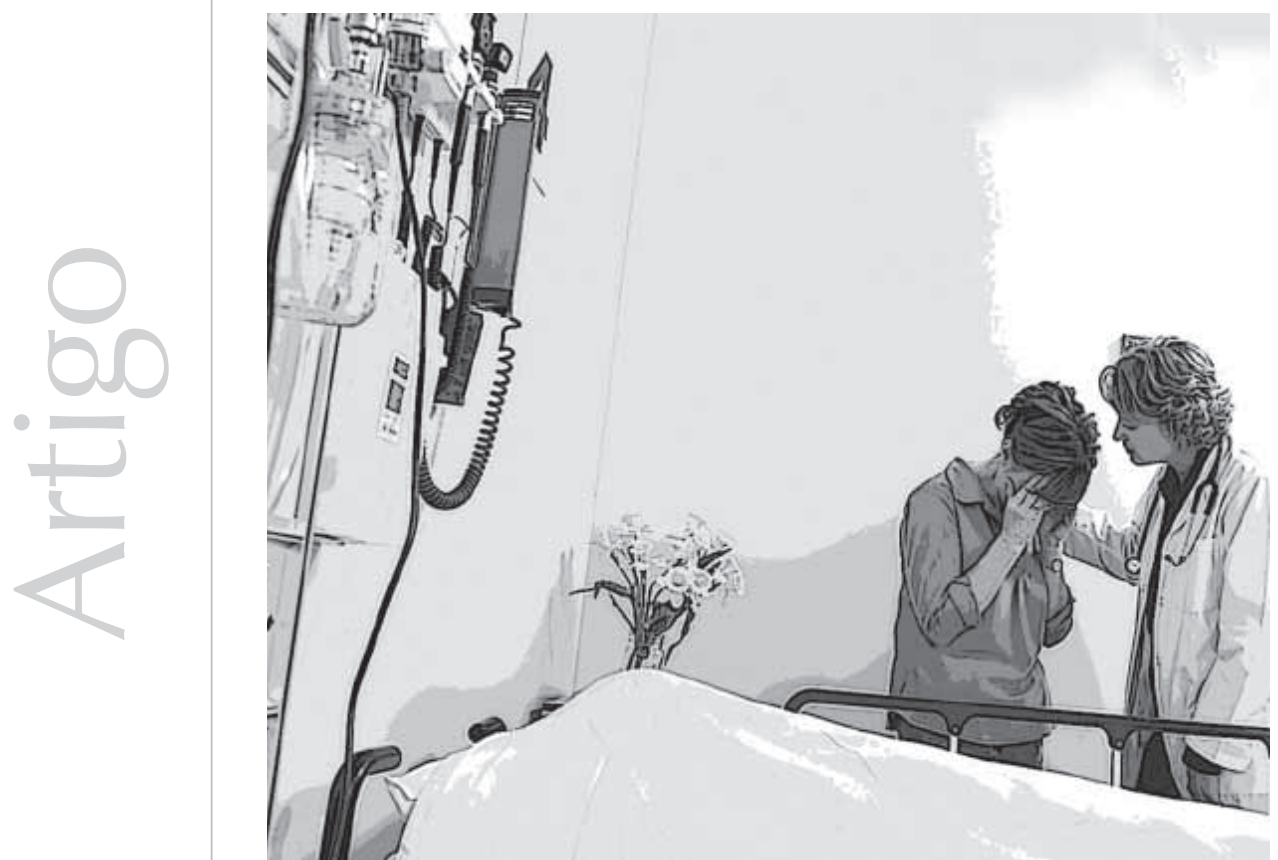
Resumo: Este artigo discute a comunicação sobre a morte em instituições de saúde, e foi baseado nos dados de uma pesquisa que teve os seguintes objetivos: verificar como é a comunicação sobre a morte em instituições de saúde e residenciais para idosos, as dificuldades que os profissionais de saúde que trabalham nessas instituições apresentam em relação à comunicação sobre a morte, analisar os filmes do projeto Falando de Morte como elementos facilitadores na comunicação sobre a morte e propor e analisar grupos de reflexão e discussão sobre o tema com profissionais de saúde nas instituições mencionadas. Utilizou-se a modalidade da pesquisa-ação. Em atividades didáticas e em grupos de reflexão, foram aplicados questionários que envolviam esse assunto nas instituições pesquisadas. Os dados mostraram que cabe ao médico, e não à equipe, falar sobre a morte com pacientes e familiares. Os médicos não se sentem preparados para abordar o tema da morte, que é visto como tarefa de ninguém, já que é função de profissionais de saúde manter a vida. Nas instituições para idosos, o tema é interdito. Os profissionais afirmam que não é sua função falar sobre a morte com idosos porque esse assunto causa sofrimento. Ter preparo para falar sobre morte ajudaria a compreender e a cuidar melhor dos idosos. Os filmes do projeto Falando de Morte foram analisados e considerados instrumentos facilitadores na preparação de profissionais de saúde no cuidado a pessoas que vivem situações de perdas e de morte.

Palavras-chave: Morte. Profissionais de saúde. Organizações. Atitudes frente a morte.

Abstract: This article discusses communication about death in health institutions based on a research that had the following objectives: verify how is the communication about death made in health institutions and long permanence institutions for old people, the difficulties the health professionals who work in these institutions have concerning the communication about death, analyze the films of the project Talking about Death as tools to facilitate the communication about death and propose and analyze discussion groups about the issue in these institutions. The modality of research-action was utilized. In didactic activities and in discussion groups questionnaires about death and health institutions were applied. Data showed that it is the physicians' task to talk about death with patients and families, not the health team's task. Physicians feel that they are not prepared to deal with the issue of death, that is considered nobody's task, since it is expected of health professionals to save lives. In the institutions for aged persons death is an interdict subject. Professionals state that it is not their function to talk about death with the aged residents because it causes suffering. Being prepared to deal with death would help to understand and improve care to aged people. The films of the project Talking about Death were analyzed and considered facilitating tools in the preparation of health professionals who give care to people who undergo situations of loss and death.

Keywords: Death. Health professionals. Institutions. Death attitude

Resumen: Este artículo discute la comunicación acerca de la muerte en instituciones de salud, y se ha basado en los datos de una investigación que ha tenido los objetivos que se enumeran a continuación: verificar cómo es la comunicación acerca de la muerte en instituciones de salud y en hogares de ancianos; las dificultades que los profesionales de salud que trabajan en esas instituciones presentan en lo que tañe a la comunicación acerca de la muerte; analizar las películas del proyecto "Hablando de la Muerte" como elementos facilitadores en la comunicación acerca de la muerte; y proponer y analizar grupos de reflexión y discusión acerca del tema con profesionales de salud en las instituciones mencionadas. Se ha llevado a cabo la modalidad de la investigación-acción. En actividades didácticas y en grupos de reflexión, se han aplicado cuestionarios que mencionaban ese tema en las instituciones investigadas. Los datos han demostrado que le toca al médico, y no al equipo, hablar acerca de la muerte con pacientes y familiares. Los médicos no se sienten preparados para mencionar el tema de la muerte, que es visto como una tarea de nadie, ya que es función de los profesionales de salud mantener la vida. En los hogares de ancianos, ese tema es prohibido. Los profesionales han afirmado que no es su función hablar acerca de la muerte con ancianos porque ese tema provoca sufrimiento. Tener preparación para hablar acerca de la muerte ayudaría a comprender y a cuidar mejor los ancianos. Las películas del proyecto "Hablando de la Muerte" han sido analizadas y consideradas instrumentos facilitadores en la preparación de profesionales de salud en el cuidado a las personas que pasan por situaciones de pérdidas y de muerte.

Palabras clave: Muerte. Profesionales de Salud. Organizaciones. Actitud frente la muerte. 
A morte escancarada invade a vida das pessoas, pela violência, por ser inesperada, dificultando a elaboração do luto. Esse tipo de morte é apresentada na $\mathrm{TV}$, inundando domicílios com uma torrente de imagens de mortes, com diversas representações nos noticiários, novelas, filmes e documentários (Kovács, 2003c).
Várias mentalidades diante da morte se fazem presentes no início do século XXI: a morte interdita, a reumanizada ou a escancarada (Kovács, 2003c). Ariès (1977), ao se referir à morte interdita, cita atributos como: vergonha, fracasso, erro médico. Esse tipo de morte constitui evento solitário, e a expressão do sofrimento deve ser minimizada, sem rituais. A caricatura que melhor a representa é a do ser humano que não pode morrer, com tubos em todos os orifícios do corpo, tendo por companhia ponteiros e ruídos de máquinas. O ser humano fica, assim, expropriado de sua morte. O silêncio impera, tornando penosa a atividade dos profissionais de saúde com pacientes gravemente enfermos. O prolongamento da vida e do tempo da doença amplia o convívio entre pacientes, familiares e equipe de cuidados, com aumento do estresse e risco de colapso.

Ao se priorizar, no hospital, salvar pessoas a qualquer custo, a ocorrência da morte pode fazer com que o trabalho da equipe de saúde seja visto como frustrante e sem significado, uma das principais razões para o estresse e o colapso, conhecidos como síndrome de Burnout. Não conseguir evitar, adiar a morte ou aliviar o sofrimento pode trazer ao profissional a vivência de seus limites, da sua impotência e finitude (Carvalho, 2004).

Com o avanço da tecnologia médica, os profissionais se preocupam com a manutenção da vida, tendo que cuidar de ponteiros e luzes que monitoram as funções vitais de seus pacientes. Conversar com eles, ouvir seus sentimentos e suas emoções fica, nesses casos, relegado a segundo plano diante da batalha contra a morte (Silva, 2002; Kovács, 2003a).

A morte reumanizada é abordada inicialmente por duas autoras: Kubler-Ross e Cicely Saunders, que cuidaram de pacientes e de familiares na aproximação da morte, acolhendo o sofrimento e dor. O paciente volta a ser o centro da ação, resgatando-se o processo de morrer (Ariès, 1977; Kovács, 2003b, 2007).

A morte escancarada invade a vida das pessoas, pela violência, por ser inesperada, dificultando a elaboração do luto. Esse tipo de morte é apresentada na TV, inundando domicílios com uma torrente de imagens de mortes, com diversas representações nos noticiários, novelas, filmes e documentários (Kovács, 2003c).

Observa-se que, ao mesmo tempo em que é interdita, a morte torna-se companheira cotidiana na vida das pessoas, invasiva, sem limites, próxima também de crianças e de adolescentes. O aumento dos casos de Aids e de câncer faz com que jovens fiquem hospitalizados por longos períodos, privados de brincadeiras, dos amigos, das atividades escolares, das relações amorosas, da formação da identidade, e convivam com a perspectiva da morte. Essa dualidade está também presente na concepção de que não se deve falar sobre a doença com pacientes, o que resulta em distúrbios na comunicação gerados pelo processo de adoecimento, situação muito comum em oncologia pelo estigma e pela representação da doença ainda ligada à dor e ao sofrimento. Essa situação é conhecida como conspiração do silêncio (Kovács, 1992, 2003b).

Schultz e Schlarb (1987/1988) afirmam que é importante falar sobre a morte com pacientes que se encontram em um estágio avançado da doença, agora em maior número graças a novos tratamentos médicos. As questões são: agravamento da doença, sintomas múltiplos e incapacitantes, transmissão de más notícias, enfrentamento da proximidade da morte e processo do luto antecipatório (Fonseca, 2004).

A Association for Death Education and Counselling (ADEC) foi fundada em 1976, 
nos Estados Unidos, com estes objetivos: 1.oferecer oportunidades de interação entre seus membros, estabelecendo redes de contato, 2. promover encontros, workshops e material escrito para divulgar o assunto e 3. incrementar a educação para a morte e as possibilidades de intervenção. Foram estabelecidas diretrizes para profissionais e estudantes, e especialistas foram certificados. Preparou-se catálogo com as principais referências sobre o tema, tendo sido organizados currículos de tanatologia. Stillion (1989) enfatiza a necessidade de preparar profissionais habilitados para criar e oferecer cursos com vários formatos. O periódico Death Studies é o porta-voz dessa associação, e, com o Omega, o Journal of Death and Dying oferece conhecimento, pesquisas e práticas profissionais sobre o assunto.

Em universidades brasileiras, estão se formando núcleos de estudos e pesquisas sobre o tema. Um dos primeiros foi o Núcleo de Estudos e Pesquisas sobre Tanatologia (NEPT -UFRJ), fundado por Wilma Torres, pioneira na área de estudos sobre a morte no Brasil. Foi criado o Laboratório de Estudos sobre o Luto (LELU - PUCSP), coordenado por Maria Helena Pereira Franco, e o Laboratório de Estudos sobre a Morte (LEM-USP), coordenado por Maria Julia Kovács. Em consulta ao diretório de pesquisas do $\mathrm{CNPq}$, identificamos grupos de pesquisa em tanatologia em várias partes do País: a) Bio Tanatos. Educação: interfaces formativas, na UNEB (Bahia), coordenado por Valdeci dos Santos, b) Laboratório de Tanatologia e Psicometria na UFF (Rio de Janeiro), coordenado por Adriana Cardoso de Oliveira e Silva, c) Núcleo de Estudos e Pesquisas em Tanatologia e Subjetividade, na UFRJ (Rio de Janeiro), coordenado por Rogério Lustosa Barbosa e Lígia Py e d) Saúde Mental e Tanatologia, da UFMA (Maranhão), coordenado por Widoberto Batista Gurgel.

Embora o tema da morte seja tabu, observase aumento das pesquisas, da discussão e das reflexões sobre o assunto, que envolve pessoas no fim da vida ou enlutadas. Franco (2002, 2010) apresenta as novas vertentes para o estudo do luto, com revisão de diretrizes para pesquisa, enfatizando a importância do consentimento informado, com a preocupação de não aumentar o sofrimento dos pesquisados. Busca-se beneficência, autonomia e dignidade, analisando-se cuidadosamente cada situação, em especial quando há pessoas em grande sofrimento, como pacientes gravemente enfermos, familiares e profissionais de saúde (Kovács, 2009). A decisão deve ser voluntária, sem nenhuma coerção ou pressão. Essa questão é mais importante se as pesquisas forem realizadas em hospitais, já que pacientes podem ter medo de que a sua não aceitação em participar possa desagradar profissionais, o que implica prejuízo do tratamento.

\section{Profissionais de saúde}

O crescente desenvolvimento técnico da Medicina e dos hospitais provocou o deslocamento do lugar da morte, que raramente ocorre em casa. O fim de vida pode ser acompanhado de muito sofrimento, e pacientes e familiares podem se sentir abandonados. Médicos e enfermeiros estão sobrecarregados, tendo que realizar procedimentos com os quais nem sempre concordam. Embora a maioria das mortes ocorra nos hospitais, é também esse o lugar em que se percebe a sua ocultação (Pessini, 2004).

A morte, na atualidade, pode ser vista como derrota, fracasso, e leva à percepção dos limites na busca da cura ou do prolongamento da vida, o que causa sofrimento aos profissionais envolvidos (Steytler, 2007; Junqueira, 2008; Souza, Soares, Costa, Pacífico, \& Parente, 2009). Rezende (2000) refere-se ao desafio de cuidar de pacientes em estágio terminal, não com abandono ou passividade, e sim, com participação, tendo a morte não como 
Os profissionais de saúde vivem processos de luto pela perda de alguns de seus pacientes, entretanto, tratase de luto não autorizado, já que não têm permissão de expressar os seus sentimentos (Doka, 1981; Casellato, 2005). adversária, mas como companheira e conselheira.

Hennezel (2001) define morte roubada como o apressamento da morte sem o pedido explícito do paciente, porque seu sofrimento agride quem cuida dele. Esse procedimento interrompe o contato, as despedidas e o compartilhamento de sentimentos, que a proximidade da morte exige. Os hospitais são os locais onde mais se pratica a morte roubada.

Cabe à Medicina cuidar de pessoas, combater doenças, e não o doente. A atitude de tentar preservar a vida a todo custo é responsável por um dos maiores temores do ser humano na atualidade: ter a vida mantida com muito sofrimento, ficar solitário em uma UTI, na companhia de tubos e máquinas.

Observam-se atualmente alterações significativas nas formas de morrer, principalmente no que concerne à sua extensão. Há predominância de doenças crônicas, cardiopatias, câncer, enfermidades neurológicas e Aids. O grande medo dos pacientes é o subtratamento de sintomas e o supertratamento na UTI, prolongando o processo de morte, o que configura um paradoxo. Talvez seja esse o motivo para debates frequentes sobre eutanásia, suicídio assistido e cuidados paliativos (Pessini, 2004). As mortes nas UTIS podem envolver processos complexos, com grande risco de se promover a distanásia. Está longe de haver consenso nesses casos, e Schramm (2002) ressalta que a definição dos termos é fundamental quando se considera essa questão. Muitos processos distanásicos são realizados com pacientes gravemente enfermos para evitar o que erroneamente se define como eutanásia, entendida como o apressamento da morte. O que se observa em muitos casos é que se promove a distanásia, impedindo-se o processo natural da morte, e não o da eutanásia. É nessa forma de encarar e combater a morte que podem ocorrer algumas das mortes indignas de nosso tempo, prolongadas, com grande sofrimento e solitárias.

A morte traz para os profissionais de saúde a possibilidade de entrar em contato com os seus processos de morte e finitude. Estes vivem a angústia de ter que salvar a vida do paciente a todo custo, realizando procedimentos que aumentam o sofrimento e a dor. Devem tomar decisões e, com frequência, sentem-se sozinhos, impotentes, com dificuldade para abordar familiares, que fazem perguntas constantes sobre a evolução do paciente. São frequentes os sentimentos de fracasso (Esslinger, 2004).

Os profissionais de saúde vivem processos de luto pela perda de alguns de seus pacientes, entretanto, trata-se de luto não autorizado, já que não têm permissão de expressar os seus sentimentos (Doka, 1981; Casellato, 2005).

Estratégias defensivas podem ser acionadas, como apontam Quintana, Kegler e Maucha (2006), principalmente diante de pacientes que se encontram em estágio avançado da doença e próximos da morte. Os profissionais podem se sentir derrotados, quando veem a morte como adversária. Para Machado e Merlo (2006), é fundamental reconhecer os aspectos existenciais do sofrimento de quem cuida, ajudando na construção da identidade de um cuidador mais humano. Esses autores estudaram o desenvolvimento de estratégias coletivas e individuais ao enfrentar uma realidade que gera sofrimento. Entre as principais defesas, podemos citar: somatização, negação do fato, ocultação da dor e banalização do sofrimento. Defesas são meios de sobrevivência psíquica, mas não eliminam, e sim, tamponam o sofrimento, levando a escapes ou a transbordamento de emoções que interferem na relação médico-paciente e que, no extremo, geram a síndrome de Burnout. 
Martins (2004) discute a onipotência que se manifesta frente à impotência com o avanço da doença e com a impossibilidade de cura. Nem onipotência nem impotência, o que se propõe, nos cursos de formação ou em serviço, é o desenvolvimento do potencial de cuidados dos profissionais de saúde.

Alguns profissionais não sabem como manejar a dor e outros sintomas incapacitantes, e se afastam de seus pacientes. Hennezel (2001) destaca que muitos pedidos de eutanásia desapareceriam se os doentes se sentissem menos solitários e sem dor. Quando o doente pede para morrer, deseja ter seu sofrimento e sua dor acolhidos. Mishara (1999) observa o aumento dos pedidos de eutanásia nos últimos anos, relacionados ao prolongamento da vida, sem preocupação com sua qualidade.

Mota (1999) afirma que tratamentos que prolongam a vida sem garantia de melhora ou de qualidade são propostos porque é difícil assistir à pessoa durante seu processo de morte e sentir que não se está fazendo nada. Para alguns profissionais, o tratamento envolve ações efetivas, e, em uma época com tantas novas tecnologias, estas podem ser usadas como tentativa de aliviar a sensação de impotência frente à morte.

Esslinger (2004) e Gutierrez (2003) destacam que frequentemente profissionais se dizem despreparados diante da morte e do morrer, referindo-se ao fato de não terem discutido o tema na sua formação. Afastam-se do paciente, pois temem envolver-se, perder a objetividade e serem criticados por isso.

Segundo Steytler (2007) e Junqueira (2008), a formação de profissionais, principalmente de Medicina, tem como ênfase a técnica, e não os fatores psicossociais. O primeiro contato desses jovens com a morte se dá pelo estudo da anatomia em cadáveres, uma forma de morte despersonalizada. Na formação de médicos, segundo Silva e Ayres (2010), são propostas as humanidades médicas, disciplinas e atividades que envolvem reflexão sobre como os alunos lidam com saúde, doença e sofrimento. Os autores propõem cenas para alunos de Medicina no seu confronto com a morte, ao atender pacientes gravemente enfermos. Ao dramatizar, eles lidam com sentimentos, com insights e com novas possibilidades de ação.

\section{Educação para a morte}

O prolongamento da vida e o avanço da técnica médica trouxeram um convívio maior com os processos de morrer para familiares e profissionais da área de saúde. Vê-se o paradoxo: por um lado, a necessidade de ocultar, de escamotear a morte, e, por outro, a preocupação de abrir espaços de compartilhamento pela maior convivência com a morte.

Os cursos sobre a morte e o morrer se desenvolveram na década de 1970 em vários formatos: didáticos, experienciais ou mistos, incluindo palestras e discussões em grupo. A modalidade experiencial ajuda a examinar sentimentos e preocupações em relação à morte, e envolve as esferas cognitiva, afetiva e comportamental (Kovács, 2003).

Uma dúvida é se os profissionais estarão mais preparados para enfrentar e aceitar a morte após participarem desses cursos. Essa relação não é direta, os cursos promovem sensibilização e reflexão sobre os temas abordados, abrindo-se novos horizontes. Leviton (1975) realizou estudo sobre o que motiva as pessoas a escolher cursos sobre a morte e o morrer, observando o seguinte: a) curiosidade e interesse, b) superar problemas pessoais frente à morte, c) aprofundar questões sobre o tema da morte, d) ajudar pessoas a lidar com a própria morte e com a dos outros, e) preparar-se para a própria morte. São motivações que 
incluem aspectos cognitivos e emocionais e envolvem o cuidar de si e de outros. Segundo o autor, as pessoas podem buscar o curso como processo terapêutico por estarem vivenciando perdas ou porque pensam em suicídio. Determinados conteúdos mobilizam os alunos, e dão espaço aos sentimentos, tendo efeito terapêutico (Kovács, 1992, 2003).

Johansson e Div (1990/1991), Durlak e Riesenber (1991), Hayslip, Galt e Pinder (1993/1994), Glass Jr. (1990), Knight e Elfenbein (1993), Mc Farland, Rollim, Gonzalez e Rhoades (1994) e Maglio \& Robinson (1994) realizaram estudos para verificar os efeitos dos cursos, destacando sua potencialidade de oferecer reflexões sobre a prática vivida ou subsídios para profissionais, estudantes e estagiários, para que cuidem melhor de pessoas que vivem situações de morte.

A experiência de cursos sobre a morte no Brasil foi iniciada por Wilma Torres, que, em 1980, propôs o Curso de Especialização em Tanatologia no Rio de Janeiro, que envolvia discussão e reflexão sobre o tema da morte. Torres organizou o primeiro banco de dados brasileiro sobre tanatologia. Em 1986, foi oferecida a disciplina Psicologia da Morte na graduação em Psicologia do Instituto de Psicologia da USP (Kovács, 1989, 2003).

\section{Projeto Falando de Morte - filmes educativos ${ }^{1}$}

1 Referências ao projeto Falando de Morte podem ser consultadas em Kovács, M. J. (2003), Educação para a Morte. Desafios na Formação de Profissionais de Saúde e Educação. São Paulo, Casa do Psicólogo.
Os filmes que compõem o projeto Falando de Morte são destinados a crianças, adolescentes, adultos, idosos, famílias e a profissionais de saúde e educação, e têm caráter preventivo, abordando os temas morte, perdas, adoecimento, luto e comportamentos autodestrutivos, que proporcionam, a partir de cenas cuidadosamente escolhidas, contato com experiências vividas e nem sempre elaboradas. Os filmes oferecem subsídios para profissionais, fundamentando seu trabalho com pacientes que estão vivendo experiências de morte.

O projeto compõe-se de quatro filmes:

Falando de Morte: a Criança (1997, modificado em 2004), Falando de Morte com o Adolescente (1999, modificado em 2002), Falando de Morte com o Idoso (2001) e Falando de Morte com os Profissionais de Saúde (2004).

Os filmes apresentam descrição inicial da motivação para construí-los, levando em conta a especificidade da faixa de desenvolvimento a que se destinam.

\section{Filme 1- Falando de Morte com a Criança}

Esse filme enfoca dois aspectos: a morte do outro, o processo de luto e a morte de si no adoecimento. Procura-se familiarizar crianças com sentimentos, dúvidas e angústias decorrentes de situações de perda e morte, mostrando que essas experiências podem ser compartilhadas e elaboradas. No que se refere à morte do outro, procurou-se enfatizar que ocorre com todos os seres humanos, podendo ser repentina ou anunciada. Foi dado enfoque ao rompimento de vínculos, trazendo à tona os sentimentos e o desejo de reunião com a pessoa morta. Buscou-se destacar o sentimento de culpa com relação à morte de alguém amado, que pode gerar sofrimento, já que a morte é irreversível, fato que a criança no período pré-operacional terá que aprender.

A própria morte traz a questão do adoecimento, dos sentimentos, do medo da morte, dos procedimentos hospitalares, invasivos e dolorosos, e a do medo da separação de pessoas queridas. A família em desequilíbrio pela doença e pela aproximação da morte é também questão abordada no filme. 


\section{Filme 2 - Falando de Morte com o Adolescente}

Esse filme procura se adequar à linguagem de adolescentes, focando principalmente os comportamentos autodestrutivos.

A morte está próxima dos jovens, já que ocorre nas ruas, e tem presença diária na TV, com cenas de violência, acidentes e doenças. O filme oferece oportunidade para reflexão e discussão sobre o tema, com cenas de esportes radicais, violência, amor, sexo, uso de drogas, acidentes e tentativas de suicídio, mostrando como a vida do jovem está exposta a riscos. Há imagens acompanhadas de questões e pontos de reflexão, que permitem aos adolescentes participar da discussão com os pais, educadores e profissionais de saúde, que assim se aproximam do universo de seus filhos e alunos. O filme pode ser instrumento didático em sala de aula ou assistido em casa.

\section{Filme 3 - Falando de Morte com o Idoso}

Nesse filme, são abordadas as perdas vividas no processo do envelhecimento de pessoas da mesma faixa etária, como o cônjuge ou os amigos, e pode trazer o sentimento de solidão. Há também a perda de filhos adultos, que traz um duplo problema: lidar com a perda do filho e do cuidador.

O filme procura trazer para o idoso, para seus familiares e profissionais de saúde e educação um meio de facilitar a comunicação sobre perdas e morte. Enfoca as seguintes temáticas: saúde e doença, perda de si, perda do outro; perda contra si: suicídios e comportamentos autodestrutivos.

\section{Filme 4 - Falando de Morte com os Profissionais de Saúde}

Esse filme foi elaborado com linguagem técnica e propõe reflexões sobre os seguintes temas: o desenvolvimento humano e a questão da morte, pacientes gravemente enfermos e a aproximação da morte, perdas e processo de luto, suicídio e comportamentos autodestrutivos, bioética e profissionais de saúde e morte.

Apresentam-se nesse filme as possibilidades de comunicação com o paciente, de ouvir e acolher dúvidas sobre o prolongamento da vida, os tratamentos propostos e o favorecimento da autonomia em relação à própria vida e à morte.

\section{Descrição da pesquisa:} Instituições De Saúde E A Morte. Do Interdito À Comunicação - pesquisa com bolsa produtividade do $\mathrm{CNPq}$

Apresentamos a seguir os objetivos, o método e os dados obtidos em vários sub-projetos que compõem o projeto citado.

Os objetivos foram:

1. Verificar como é a comunicação sobre a morte em instituições de saúde e residenciais para idosos;

2. Verificar as dificuldades que profissionais de saúde que trabalham nessas instituições apresentam em relação à comunicação sobre a morte;

3. Analisar os filmes do projeto Falando de Morte como elementos facilitadores na comunicação sobre a morte;

4. Propor e analisar grupos de reflexão e discussão sobre o tema da morte com profissionais de saúde nas instituições mencionadas.

Adotamos a abordagem qualitativa dos dados obtidos, procurando detectar os significados inerentes às práticas dos profissionais de saúde em relação à morte, como propõe Minayo (2000). O trabalho foi realizado em instituições de saúde e em instituições residenciais para idosos a fim de compreender 
a relação dos profissionais com a questão da morte no seu cotidiano de trabalho. Destacamos a importância da experiência direta dos participantes do projeto para a compreensão da realidade estudada.

Utilizamos a modalidade pequisa-ação como postulada por Thiollent (1986), delineando a investigação associada a intervenções para um problema no qual pesquisador e participantes estão envolvidos de modo cooperativo interativo e participativo. No caso deste projeto, os profissionais de saúde participantes e a pesquisadora buscam construir o conhecimento sobre a facilitação da comunicação sobre a morte nas instituições estudadas. Procuramos, durante a exibição dos filmes do projeto Falando de Morte e a discussão nos grupos, as questões propostas nos objetivos da pesquisa, detectando os significados e sentidos a elas atribuídos.

A partir da descrição das ações cotidianas dos profissionais, procuramos captar singularidades, como proposto por Schutz (1979). Nos momentos de reflexão e distanciamento proporcionados pelos grupos, foram discutidas as ações que fazem parte das práticas rotineiras nas instituições estudadas.

Esse projeto está em andamento, e o que ora apresentamos é uma parte dos dados já obtidos. Em um primeiro momento, a pesquisa teve caráter exploratório, e buscou compreender como os profissionais de saúde lidam com a morte nas instituições nas quais trabalham. Esse conhecimento foi obtido pela coleta de relatos e pelas respostas a questionários. Em um segundo momento, foram propostas atividades facilitadoras da comunicação sobre o tema da morte, utilizando-se os filmes do projeto Falando de Morte.

Os participantes foram profissionais de instituições de saúde, contatados pelo
Laboratório de Estudos sobre a Morte do Instituto de Psicologia da USP para assistir os filmes do projeto. Foram incluídos também profissionais que solicitaram colaboração para atividades de cuidados em situações de perda e morte, presentes no seu cotidiano. $\mathrm{O}$ número de participantes não foi estabelecido a priori, e os dados aqui apresentados são os daqueles que assinaram o Termo de Consentimento Livre e Esclarecido para fazer parte da pesquisa.

Na oportunidade em que foram exibidos os filmes, entregou-se questionário aos participantes com perguntas referentes à temática do filme, à sua proposta de lidar com o tema da morte e à opinião do profissional a respeito do filme como instrumento facilitador da discussão sobre o tema da morte na instituição em que trabalha. Foram considerados como dados respostas aos questionários, entrevistas e atividades de grupos; assim, procurou-se saber como é vista a questão da morte pelos profissionais participantes, observando-se a consciência crítica dos processos que ocorrem nos grupos estudados. As respostas aos questionários foram organizadas de acordo com as principais tendências, e os significados trazidos pelos participantes permitiram a coconstrução da reflexão, como propõe Spink (1999).

Essa compreensão conjunta trouxe questões e reflexões sobre como a abordagem do tema da morte ocorre em instituições de saúde e em residências para idosos. Não buscamos generalizações, e sim, reflexões que possam trazer colaborações mais abrangentes para outras instituições.

O Termo de Consentimento Livre e Esclarecido foi apresentado aos colaboradores, sendo a participação no projeto voluntária, com a garantia de sigilo, confidencialidade e privacidade. Os dados foram analisados de forma coletiva, preservando-se o anonimato da instituição e dos colaboradores. O projeto 
foi submetido ao Comitê de Ética do Hospital Universitário da USP, tendo sido aprovado em 7 de novembro de 2008.

\section{Apresentação dos dados e discussão}

Os dados estão organizados pelas instituições pesquisadas e apresentados a seguir:

I. A questão da morte nas instituições de saúde - hospitais

Técnicos de enfermagem - curso: Profissionais de Saúde: a Morte na Prática do seu Cotidiano

Vinte técnicos de enfermagem de um hospital público da cidade de São Paulo participaram de um curso de extensão sobre a questão da morte. As idades variaram de 20 a 59 anos.

Pedimos aos participantes que respondessem questões envolvendo sua compreensão da morte, como a veem no seu trabalho e como gostariam de obter o preparo para lidar com o tema, demanda cotidiana para eles. Apresentamos a seguir as respostas:

\section{O que é a morte para você?}

É o fim de um ciclo, traz angústia e tristeza, perda, passagem para uma nova dimensão na qual o espírito continua, saudade, partida, silêncio, fim do corpo.

$75 \%$ dos técnicos de enfermagem afirmaram que tinham dificuldades para lidar com o sofrimento dos familiares e para se comunicar com eles. Não sabiam como lidar com pacientes que não aceitam a morte e que tinham dificuldades de elaborar a perda de pacientes com os quais tiveram contato mais intenso. As mortes repentinas também causam sofrimento. $70 \%$ relataram que não se sentiam preparados para lidar com a morte.
Os que se sentiam preparados referiram-se às experiências pessoais.

Quando perguntados sobre como gostariam de ser preparados para lidar com essas situações, alguns se referiram à forma, outros, ao conteúdo. Entre as propostas, estão: exemplos de situações reais, como se comportar na sua função profissional, como não se envolver psicologicamente, como aceitar melhor a morte e obter apoio psicológico.

No questionário aplicado após o término do curso, verificamos diferenças na forma de ver a morte. A totalidade dos pesquisados respondeu que houve diferenças, apontando os seguintes aspectos: acertar no modo de lidar com os pacientes, não apresentar frieza no cuidado, pensar em questões éticas, adquirir maior segurança e tranquilidade, envolver-se mais com os pacientes, entender melhor quem está sob seus cuidados, ouvir perguntas, poder chorar e ver a morte como parte do seu trabalho.

Os pontos mais significativos no curso foram: falar abertamente sobre a morte, aprender a lidar com a morte no cotidiano, responder ao paciente se vai morrer, lidar com pacientes suicidas, cuidar da família. Gostariam de aprofundar os seguintes assuntos: cuidados paliativos, suicídio, perdas e processo de luto, eutanásia e distanásia, questões éticas, pacientes com câncer, compreensão e abordagem da família.

Profissionais de enfermagem

(enfermeiros e técnicos de enfermagem) - Avaliação do filme: Falando de Morte com Profissionais de Saúde

Colaboraram 24 enfermeiros de um hospital público da cidade de São Paulo. A atividade incluiu a exibição do filme Falando de Morte com Profissionais de Saúde, a resposta ao 
questionário sobre o filme e a participação em grupo de discussão. Os participantes eram das seguintes unidades: pediatria, clínica médica, pronto-socorro adulto, UTI, clínica cirúrgica, endoscopia e pronto-socorro infantil.

\section{Perguntas:}

1. Você gostou do filme?

A totalidade dos participantes disse que havia gostado do filme, e fez os seguintes comentários: apresenta questões do cotidiano com explicações e esclarecimentos sobre como lidar com a morte e comunicação sobre a morte com linguagem clara e objetiva; apresenta vários aspectos do tema da morte: luto, cuidado a pacientes terminais, morte na trajetória da vida e nas fases do desenvolvimento.

2. Qual o aspecto do filme que chamou a sua atenção?

Explicar a morte para as crianças, cuidar de pacientes terminais, luto, dificuldade de aceitar a morte, distanásia, cuidar da família, suicídio, morte nas fases do desenvolvimento, complexidade da morte, unidades de terapia intensiva, depoimentos de profissionais de saúde, cuidado ao cuidador, a questão do idoso, síndrome de Burnout. As questões destacadas estão relacionadas com a prática hospitalar desses profissionais.

\section{O que mudaria no filme?}

$58 \%$ dos enfermeiros responderam que não mudariam nada, $42 \%$ fizeram sugestões e críticas: incluir narrativas de quem vivenciou situações de morte, editar o filme, alguns textos são redundantes, dedicar mais tempo ao tema do suicídio, falar mais sobre enfermagem, explicitar melhor a questão da eutanásia, da distanásia e dos pacientes terminais.

4. O que é a morte para você?

Evoca sentimentos: tristeza, medo, causa sofrimento, angústia, difícil de comunicar-se com a família, é inevitável, perda dos filhos, certeza para todos, consequência da vida, alívio para pacientes terminais, passagem, natural, fria, morte inesperada é difícil, é rotina para o profissional. Há uma amplitude de respostas. Destaca-se a manifestação do sofrimento e de sentimentos como medo, angústia e tristeza, presentes na maior parte das respostas. Ressaltam que é mais fácil lidar com a morte no âmbito profissional do que no pessoal.

5. Como você vê a morte na instituição em que trabalha?

As respostas foram: tema pouco abordado, de difícil aceitação, distanásia presente, necessidade de cuidar da família, negação dos profissionais, é tratada de forma superficial, há indicação para que os profissionais não se envolvam com os pacientes, a morte acarreta muitas situações difíceis, não se escutam pacientes, há necessidade de mais informações. A tendência que se observa é a dificuldade de abordagem do tema da morte, a superficialidade e a negação. Há uma ênfase na questão da distanásia, o que, do nosso ponto de vista, é uma questão urgente a ser estudada nos hospitais, e envolve o dilema do prolongamento da vida, com prejuízos à sua qualidade, com muito sofrimento. Como muitos dos participantes trabalham com idosos, em unidades de terapia intensiva, esse problema é frequente e relevante.

6. Você acha que a instituição deveria abordar o tema da morte?

96\% dos enfermeiros, a quase totalidade, afirmou que sim. Entre os motivos apontados, estão: debate para diminuir o sofrimento, palestras sobre o tema, trabalho em grupo, cuidado a pacientes terminais (câncer) e família, lidar com perdas.

A quase totalidade dos profissionais entrevistados acredita que a instituição deve abordar o tema da morte. Vê-se 
que há a expectativa de que a morte seja abordada no hospital. Os profissionais apontam a necessidade de propor atividades que envolvam os temas sugeridos pelos profissionais e como querem ser preparados para essa tarefa.

7. Sente-se preparado para abordar o tema com pacientes e familiares?

Cinco participantes (21\%) afirmaram que sim, 11 (46\%) acham que em parte, e 8 (33\%), que não.

Os dados revelam que um número significativo de profissionais não se sente preparado para lidar com pacientes com doença avançada. É difícil também cuidar dos familiares. Os que responderam estar preparados afirmam a necessidade de respeitar as crenças e valores do paciente e escolher o momento certo para abordar o tema.

\section{Como gostaria de receber ajuda?}

As respostas foram: cuidado psicológico, discussões, conversas com especialistas, filmes e vídeos, dinâmicas de grupo, resolver dúvidas, compartilhar experiências, preparação emocional, experiências como esta pesquisa. O pedido para cuidados psicológicos e preparação emocional foi frequente.

Após a resposta aos questionários, foi realizada uma roda de discussão. Os temas abordados foram:

1. Como falar sobre a morte com pacientes, a quem cabe a tarefa de comunicar a aproximação da morte aos pacientes - é tarefa do enfermeiro ou do médico?

2. Como cuidar de crianças gravemente enfermas?

3. Como lidar com a família de pacientes que estão na UTI, com o prolongamento da morte na unidade de clínica médica, a distanásia, e como evitá-la?

4. Necessidade de cuidados ao cuidador profissional.
Médicos - filme Falando de Morte: a Criança

Dezessete médicos de um hospital da região do $A B C$ responderam ao questionário sobre o filme Falando de Morte: a Criança.

1. Sobre o filme, $70 \%$ dos médicos o consideram bom e interessante, pois aborda vários temas com linguagem sensível, é bem elaborado e permite que se reflita sobre aspectos nos quais não se pensa no cotidiano, como é a questão da morte para crianças.

$30 \%$ apresentaram ressalvas, considerando a abordagem simplista, começo artificial, confuso, triste como a morte e monótono, e não fica claro se o filme é para crianças ou para adultos.

Cabe ressaltar que, originalmente, o filme foi destinado a crianças, mas atualmente estamos certos de que é indicado para adultos (pais, educadores e profissionais de saúde) no trato com crianças: filhos, alunos ou pacientes.

2. Mudanças ou inclusões no filme: $47 \%$ dos médicos responderam que não mudariam nada. As sugestões apresentadas foram: a abordagem do tema deveria respeitar a faixa etária do assistente, envolver mais os médicos, incluir depoimentos de quem passou pela situação (alunos, estagiários, profissionais e familiares), maior agilidade nas cenas, explicitar o objetivo do filme, oferecer respostas mais diretas. Há sugestão para a inclusão de médicos veterinários.

3. Passar o filme para crianças enlutadas ou enfermas: $70 \%$ dos médicos passariam o filme para crianças em geral, 65\%, para crianças enlutadas, e 47\%, para crianças doentes. De forma geral, profissionais propõem que o filme seja utilizado com crianças mais velhas.

Alguns colaboradores apresentam os motivos para não passar o filme para crianças: é 
preferível um contato mais próximo, já que o filme é voltado para adultos.

É importante considerar que o filme foi destinado a ser elemento facilitador para debates, e não substituto do contato pessoal com familiares, educadores e profissionais de saúde.

Perguntou-se aos médicos se tinham experiência pessoal com a morte. 94\% responderam que sim nos âmbitos pessoal e profissional, e $47 \%$ responderam que essa vivência provoca sentimentos difíceis, e que por isso se sentem desconfortáveis ao lidar com ela. É mais fácil quando têm que lidar com a morte no âmbito profissional. Afirmaram ser mais difícil lidar com a morte de pacientes com os quais têm vínculo, pois isso provoca sentimentos de impotência, angústia, culpa e constrangimento por não saberem o que fazer. $70 \%$ dos participantes responderam que se adaptam à situação, baseando-se na sua experiência e preparo para lidar com a família. Em alguns casos, a morte pode ser um alívio.

Perguntou-se aos médicos se pensavam que deveriam falar com crianças e se eram capazes de discutir o assunto com elas e com os familiares. $70 \%$ responderam afirmativamente, apontando os seguintes aspectos: a morte faz parte da vida, é preciso lidar com a realidade dos fatos, as crianças têm direito de saber, precisam se familiarizar com a morte, já que vivem perdas, deve-se responder às perguntas da criança.

Para se falar sobre a morte com crianças, são necessários cuidados: levar em conta a idade, o preparo dos profissionais e encontrar o momento certo para falar. Entre as maiores dificuldades, foram apontadas: percepção de falta de preparo e atribuição de responsabilidade à família. Falar sobre a morte pode aumentar a angústia das crianças, principalmente quando são pequenas ou estão doentes. Quando se trata da comunicação com adultos, principalmente entre profissionais, $88 \%$ dos médicos responderam que conseguem falar sobre a morte, expressando os seus sentimentos.

As dificuldades apontadas foram: comunicar a morte às famílias, aceitar a própria morte e falar da aproximação da morte com pacientes com os quais tiveram envolvimento. Observou-se que profissionais de saúde têm dificuldade de abordar as famílias quando do agravamento da doença e da proximidade da morte, principalmente nas unidades de pediatria e em UTI neo natal.

Perguntamos se o tema da morte foi abordado na sua formação e como o foi. $41 \%$ dos médicos responderam que o tema foi abordado em aulas, em estágios (quando ocorreu morte de pacientes), na disciplina de ética médica, nas UTIs. Em alguns cursos, o tema da morte foi abordado de forma superficial ou só em teoria. 59\% dos médicos afirmaram que o tema não foi abordado na sua formação.

É interessante observar que 41\% dos médicos participantes deste estudo mencionaram que o tema da morte foi contemplado na sua formação em várias situações, com debates e reflexões ou quando perderam pacientes. Podemos, a partir dessa informação, questionar o discurso genérico e defensivo de que não se aborda o tema da morte na formação de médicos, uma forma de não se comprometer com a comunicação sobre a morte com pacientes e familiares.

\section{A questão da morte nas instituições residenciais para idosos}

Os processos de perda, morte e luto no idoso - aluna de Iniciação Científica Danieli Kovács Bertolami $^{2}$ 
O filme Falando de Morte com o Idoso ainda não havia sido apresentado em instituições asilares. Esse projeto foi desenvolvido como oportunidade para que os idosos abrigados em uma instituição de longa permanência pudessem compreender como se lida com o tema da morte e verificar de que forma o filme poderia colaborar com essa discussão. Quais aspectos são favoráveis ou desfavoráveis à abertura da comunicação centrada no tema da morte nesta instituição?

Procuramos compreender como perdas, morte e luto são vividos e representados ao longo do processo de envelhecimento pelos idosos institucionalizados, pelos profissionais de saúde cuidadores desses idosos e pela instituição que os abriga. Inicialmente, o projeto incluía a participação dos idosos, que depois foi reformulada, priorizando-se a apresentação do filme Falando de Morte com o Idoso aos profissionais.

Os participantes foram membros da diretoria, profissionais de saúde e outros funcionários, tendo o projeto contado com a colaboração de 35 participantes, 25 mulheres e 10 homens, com idades que variavam de 25 a 80 anos. Toda participação foi de caráter voluntário, e os que se dispuseram a colaborar assinaram o Termo de Consentimento Livre e Esclarecido.

A instituição é uma residência para idosos localizada na cidade de São Paulo, sem fins lucrativos, e é mantida por doações. Os idosos abrigados não possuem bens materiais, recebem, no máximo, um salário mínimo por mês, e, em geral, não têm família ou não mantêm contato com ela.

O filme Falando de Morte com o Idoso foi exibido em quatro sessões, realizadas nas dependências da instituição. Terminada a exibição do filme, houve discussão em grupo, aberta para que os participantes comentassem o filme e suas impressões, opiniões e visão sobre perdas, morte e luto no processo de envelhecimento.

Foram realizadas duas reuniões com a diretoria para compreender melhor o motivo para a não exibição do filme aos residentes. Falar de morte poderia gerar problemas na instituição, porque esta procura passar a ideia de continuidade da vida em um outro plano após a morte. Quando ocorre morte de um residente, a equipe retira o corpo, que é vestido atrás de um biombo, para que os outros idosos não vejam o procedimento, e depois o corpo é conduzido à capela, ficando lá por um dia para visitas. O enterro é realizado em um cemitério público, e uma das diretoras relata aos idosos a vida do falecido. Há rituais de vários credos religiosos.

Dos 30 questionários distribuídos, quatro foram preenchidos e entregues na secretaria. Perguntamo-nos os motivos da baixa porcentagem de questionários devolvidos, sendo a participação dos profissionais voluntária, de acordo com sua disponibilidade, sem que obtivéssemos uma resposta para essa questão. Os questionários foram preenchidos marcados com a profissão de quem os preencheu. A idade variou entre 25 e 40 anos, e a apresentação e a discussão apresentadas envolvem as respostas ao questionário e ao debate que se seguiu à exibição do filme.

1) A primeira pergunta foi se gostaram do filme. As respostas afirmativas incluíram a apreciação de que o filme enfoca a realidade do idoso, a possibilidade de ter um envelhecimento sadio e feliz, segundo sua escolha. A pluralidade de temas abordados pelo filme fica explicitada. A narração em primeira pessoa que acompanha o desenrolar das cenas dá voz ao idoso, busca trazer ao expectador a realidade do envelhecimento por meio da subjetividade de quem o vivencia. O filme se distancia do formato de documento, imparcial, e sensibiliza quem o vê pelo caráter pessoal. É a voz do idoso que 
apresenta as possibilidades de vivenciar essa etapa da vida de forma ativa

2) Os pontos que chamaram a atenção foram: abordagem realista do envelhecimento, busca de qualidade de vida nessa fase do desenvolvimento e a questão do luto após perda e separação e a da saída do lar.

3) A mudança proposta foi: adaptação do filme para a realidade de instituições de longa permanência.

4) A morte é vista como passagem, realização de sonhos em outro plano, etapa natural que todos viverão. Os profissionais sentem necessidade de se preparar, porque trabalham com idosos que estão próximos da morte.

5) A morte é vista na instituição como natural, porque trabalham com idosos, e têm que lidar com perdas, que são frequentes. Sentem que é difícil falar com os idosos, porque estão próximos da morte, e falar sobre o tema pode suscitar sentimentos fortes. O preparo dos profissionais deve vir na forma de palestras e em filmes como o que foi exibido.

6) O filme foi destaque para lembrar que idosos são pessoas com personalidade, têm sua individualidade, necessidade de respeito e que deve se favorecer a possibilidade de escolha da forma de viver a velhice.

Os profissionais que responderam ao questionário afirmaram serem capazes de discutir o tema da morte com seus pacientes e familiares.

Segundo os participantes, o filme mostra os aspectos negativos do envelhecimento, como a possibilidade de o idoso ser asilado contra sua vontade ou sofrer o luto pela perda de entes queridos. Entre os aspectos positivos, estão a possibilidade de se viver bem essa fase da vida, com esperança, qualidade e autonomia. Os aspectos positivos e negativos do envelhecimento refletem o equilíbrio apresentado pelo filme, uma forma realista de abordar as perdas do envelhecimento, enfatizando que a velhice é uma fase da vida, e não a antecâmara da morte.

As sugestões de alteração do filme propõem maior atenção aos idosos asilados, que têm condições materiais inferiores aos que são retratados pelo filme.

$50 \%$ dos participantes veem a morte como continuação da vida em outro plano, e assim lidam de forma mais tranquila com esse tema; $50 \%$ apontam dificuldades de experienciar a morte, sendo o luto visto como processo de elaboração ao longo da vida para lidar com perdas. Estas causam tristeza, e a consciência da própria finitude surge por ocasião da morte de pessoas amadas, envolvendo o processo de luto.

Todos os participantes afirmaram que se deve abordar a morte, especialmente em instituições para idosos. Há demanda e abertura dos profissionais para discussão do tema, e os psicólogos foram apontados como os profissionais que poderiam mediar esse debate.

O filme facilita a discussão sobre a morte, atendendo à necessidade dos idosos de falar sobre sua morte. As questões abordadas pelo filme são humanas e não dependem de condições materiais ou intelectuais, deixam esperança e trazem ao expectador a lembrança de que o idoso pode viver bem, e que os profissionais de saúde ajudam nesse processo.

Foram feitas sugestões de inclusão de depoimentos pessoais. Entre as críticas, foram registradas: não trata da realidade vivenciada pelos idosos abrigados, não leva em conta os avanços tecnológicos atuais e não apresenta o idoso como alguém que manifesta desejos. Houve certa apreensão 
quanto à apresentação do tema da morte pelos conteúdos depressivos. Essa apreensão se desfez ao verem a abordagem do filme, condizente com a realidade vivida pelos idosos na instituição.

O ponto mais discutido no filme se refere à importância de o idoso manifestar sua vontade. Os profissionais apontaram a impossibilidade de satisfazer os desejos dos idosos no contexto institucional ou familiar, e apresenta-se o conflito entre considerar o idoso uma pessoa que tem desejos ou restringir-se às limitações inerentes à vida comunitária.

Houve a percepção de que cada pessoa escolhe como envelhecer. O grupo ressalta que o filme não responde a todas as perguntas sobre a morte, mas traz ao expectador a possibilidade de que se pode viver bem até o fim da vida.

Os profissionais afirmam que os residentes não costumam falar sobre a morte, possivelmente por falta de oportunidade e intimidade. Os que o fazem se utilizam de piadas e brincadeiras, como forma de defesa, perguntando quem será o próximo a morrer. É comum, nos dias subsequentes aos falecimentos na casa, que idosos manifestem preocupações com sua saúde. A questão é abordada com os profissionais de enfermagem pelo contato diário mais próximo.

$\mathrm{Na}$ sessão realizada com a equipe de enfermagem, discutiu-se a possibilidade de envelhecer de forma consciente, elaborando as perdas. Para alguns, não há beleza no envelhecimento, que é mais assustador do que morrer. A morte é vista como a única certeza, o que pode ser assustador. Os residentes não estabelecem relacionamentos entre si, e, por isso, não passam pelo processo de luto após o falecimento dos companheiros, segundo os participantes da pesquisa.
Os profissionais falaram sobre a tristeza dos idosos por estarem na instituição, sendo que estes se sentem abandonados e cuidados por pessoas estranhas, o que se traduz em revolta ou em comportamentos agressivos para com aqueles que deles cuidam. Os participantes disseram que a visão que tinham sobre os idosos mudou muito ao trabalharem na instituição.

A saúde do idoso, principalmente a dos homens, melhora com os cuidados que recebem. Sua sexualidade se manifesta, e as mulheres da equipe se referem a comentários feitos por homens idosos e o constrangimento que provocam.

Por fim, perguntamos como a equipe imaginava que poderia ser a apresentação do filme aos idosos. Responderam que os idosos assistiriam ao filme com indiferença. Os que fossem tocados por alguma cena do filme não teriam com quem discuti-la. Os que foram favoráveis à sua apresentação aos idosos afirmaram que estariam abertos para acolher os seus sentimentos.

A diretoria acredita que o filme poderá provocar emoções intensas por abordar o tema da morte, por isso vetou a apresentação do filme aos moradores, mudando a decisão anterior. Foram feitas reuniões com a diretoria para discutir os motivos da nova decisão. As pesquisadoras não tinham como objetivo insistir na continuidade do projeto com os idosos e sim, compreender o posicionamento da diretoria em relação às consequências de se abrir discussão sobre a morte em uma instituição asilar. Na opinião da diretoria, o filme poderia provocar depressão nos idosos, pois estes teriam dificuldades de compreensão por terem pouca escolaridade, por isso, além das perdas vividas, o filme poderia causar sofrimento, trazendo à tona a consciência dessas perdas, e as diferenças socioeconômicas entre os idosos retratados no filme e os abrigados poderiam despertar raiva ou sentimento de injustiça. 
Segundo uma das diretoras, a instituição procura mostrar a morte como esperança, e o filme a retrata com tristeza, por focar a perda de entes queridos. Os abrigados em geral não têm família, não estabelecem vínculos, não passam pelo processo de luto pela morte de entes queridos. $\mathrm{O}$ filme poderia criar uma situação que não ocorre na instituição. A diretoria se coloca como responsável e portavoz dos idosos.

Há um estigma vinculado à condição do idoso, que vivencia a última etapa de sua vida com uma série de perdas: físicas, sensoriais e sociais. Sendo a morte tema tão fundamental nessa instituição, por que não debatê-lo? A partir desses dados, podemos afirmar que o tema morte foi silenciado. Houve uma sequência de mortes na época da pesquisa relatada pelas diretoras, e esse foi um dos motivos apontados para não apresentar o filme. Perguntamo-nos se não seria esse o momento oportuno para abrir a discussão sobre o tema, beneficiando os idosos.

Uma das diretoras afirma que os residentes não têm medo da morte, mas será essa a convicção dos idosos? Será que não têm medo da própria morte ou da de seus companheiros? A diretora representa os idosos em seus sentimentos? Parece haver maciça negação da morte, não permitindo que sentimentos sejam expressos, por se acreditar que não há condições de acolhimento.

A questão da morte em instituição para idosos. Profissionais de saúde filme Falando de Morte com o Idoso. Alunas bolsistas: Flávia Vidotti Fragoso e Luiza Goulart da Silva ${ }^{3}$

Alunas de Iniciação Científica. Instituto de Psicologia da USP bolsistas da Fapesp.

visão de morte que têm profissionais de uma instituição asilar da cidade de São Paulo e como os idosos sob seus cuidados utilizado como instrumento facilitador o filme Falando de Morte com o Idoso. O filme foi exibido e os colaboradores responderam a um questionário seguido por debate em grupo.

A instituição asilar filantrópica escolhida da cidade de São Paulo abriga gratuitamente idosos que não recebem cuidados de suas famílias. Atende cerca de 200 idosos com idade média de 70 anos.

Participaram deste projeto 19 funcionários. Os grupos com 4 participantes foram formados de acordo com a disponibilidade dos profissionais de saúde, permitindo, assim, que todos pudessem expressar sua opinião. Os encontros se iniciaram após breve explicação sobre a pesquisa, e os profissionais interessados em participar assinaram o Termo de Consentimento Livre Esclarecido.

Apresentamos, a seguir, as respostas dadas:

1. O que é morte para você? Respostas: passagem, final, evento doloroso.

O que mais chamou sua atenção no filme:

a) Problemas de comunicação: transmitir o que se quer, não fazer pelo idoso, mesmo que seja para seu bem, não levar em conta o que os idosos querem.

b) A velhice em si: como se preparar para o envelhecimento, já que todos vão passar por essa situação, porque podem estar mais próximos da morte.

c) A saída do idoso de sua casa: sair do lar pode suscitar sentimentos diversos; a cena que marcou foi a saída da idosa de casa, com duas malas e espaço restrito. Muitas vezes estão sós. Essa cena chama a atenção porque aconteceu na sua família. compreendem a morte, a perda e o luto. Foi d) Aceitação ou enfrentamento da velhice: quando a decisão é a vida, e não se entregar, 
necessidade de aceitação e continuidade da vida.

e) Dependência: a hospitalização e a institucionalização levam à dependência, que causa revolta, necessitar dos outros para atividades do cotidiano é dar trabalho.

Observamos nas respostas dadas pelos profissionais de saúde que o filme aborda vários temas relacionados com o trabalho do profissional na instituição e com o seu processo de envelhecimento. O que chamou a atenção no filme foi a comunicação, que está diretamente relacionada ao trabalho institucional; a saída do lar, deixando a vida em família, e a dependência.

2. Na sua opinião, as situações apresentadas no filme têm relação com sua experiência de vida? Respostas afirmativas envolveram: vivências semelhantes, relação com o trabalho e preparação para o próprio envelhecimento.

3. Você acrescentaria ou retiraria alguma cena do filme? A resposta foi: ampliaria a discussão sobre a questão da família. Houve sugestão para retirar a cena sobre suicídio, pois nada acrescenta à discussão do tema, que não é comum entre idosos. Pensamos que seria interessante ampliar a discussão sobre suicídio. Essa pode não ser uma questão recorrente em uma instituição asilar, mas precisa ser debatida na velhice, dado o grande índice de suicídios e a frequência dos pedidos para morrer de idosos enfermos, que se sentem isolados ou rejeitados.

4. Você utilizaria esse filme para conversar com os idosos dessa instituição? Por quê? 95\% dos profissionais disseram que sim, e apontaram a seguinte razão: trabalhar dificuldades do dia a dia quanto à dependência e aos problemas da velhice, para aprender coisas novas com os idosos, ajuda a lidar com a morte deles. Observa-se que grande parte dos profissionais utilizaria o filme com os residentes apontando questões cotidianas, representando a sua vivência e experiência. Alguns profissionais apontaram restrições, dizendo que não o utilizariam com todos os idosos, já que poderia abalar profundamente as suas emoções. Teriam que avaliar a sua possibilidade de compreensão. As restrições apontadas devem ser levadas em conta, o que não inviabiliza a apresentação do filme para idosos asilados. Pode-se fazer uma seleção cuidadosa, não o exibindo àqueles que estejam deprimidos ou com déficits cognitivos. O filme desperta sentimentos e emoções, o que pode ser positivo. Entretanto, observamos o temor de despertar emoções como se estas causassem sofrimento intolerável, sem possibilidade de elaboração. As emoções são formas de comunicação importantes, que não deveriam ser tamponadas. O filme pode ser utilizado com profissionais, resultando em reflexões sobre sua prática com os idosos.

5. Como você acha que os idosos reagem ao filme e à morte no cotidiano? Respostas: dificuldade de lidar com o tema, aceitação ou conformidade, morte poderá desencadear lembranças, os idosos podem se reconhecer nas cenas apresentadas, alguns não aceitam a morte, entram em depressão, podem chorar, porque não aceitam suas limitações, sentiriam medo, insegurança e preocupação.

Os profissionais afirmam que os idosos poderiam manifestar aceitação, conformidade ou resignação quando a morte fosse vista como vontade de Deus; pode ser vista como alívio, quando há sofrimento; suscita lembranças da família, e o filme pode reabrir feridas ainda não cicatrizadas. A morte é assunto delicado e difícil, mas necessário. Os idosos podem se sensibilizar com o filme, pois já passaram por situações de perda, abandono e sofrimento; podem ver a morte como solução para seus problemas, estão velhos e não precisam mais viver. Segundo o ponto de vista dos profissionais, idosos têm dificuldade de lidar com a morte mais próxima, sentem 
medo. Aceitação ou conformidade surge como forma de lidar com a proximidade da morte. Quando o sofrimento é muito grande, a morte pode traduzir descanso.

Podemos observar que são temas amplos e variados que envolvem a questão da morte e que deveriam merecer destaque na discussão com idosos e profissionais de instituições residenciais para idosos.

\section{Considerações finais}

A abordagem do tema da morte nas instituições de saúde mostra que, embora a morte seja acontecimento frequente nos hospitais, observa-se que há dificuldade de abordagem do tema. O que se verifica é que cabe a um profissional, e normalmente o indicado é o médico, abordar a questão da morte com pacientes e familiares. Os médicos, por sua vez, ressaltam que não tiveram preparo na graduação e sentem dificuldade para abordar o tema, principalmente nas situações que envolvem mortes inesperadas ou de crianças. Observa-se um jogo de empurra, não um trabalho de equipe, em que o conjunto de profissionais responsáveis pensa sobre como realizar essa tarefa, nunca fácil, mas que poderá ser mais confortável se for considerada preocupação de todos. Comunicar a aproximação da morte é mais difícil quando se trata de crianças ou para familiares.

Não se sentir preparado para lidar com a morte foi resposta comum nas respostas aos questionários e dinâmicas realizadas. Pensamos que, em alguns casos, alegar falta de preparo pode ser defesa para não enfrentar essa tarefa percebida como tão difícil; pode também denunciar falhas na formação desses profissionais.

Uma outra hipótese é que a comunicação sobre a morte no hospital constitui uma tarefa de ninguém, já que é fala corrente que a função principal dos profissionais de saúde é manter a vida. Comunicação sobre a morte a pacientes gravemente enfermos e a familiares não é ação designada a nenhum dos profissionais no hospital.

As atividades de preparação e supervisão de profissionais de saúde em hospitais envolvem o estímulo do trabalho de equipe, identificando-se as melhores formas de lidar com a questão da morte em relação a pacientes e familiares. Acreditamos que esta também possa ser uma forma de estimular a discussão sobre perdas, morte e processos de luto entre membros da equipe de saúde dos hospitais.

Poderíamos sintetizar que o interdito da morte nas instituições de saúde está na decisão de qual profissional da equipe vai comunicar a pacientes e familiares a aproximação da morte. Percebe-se que essa é preocupação de todos.

Nas instituições residenciais para idosos que participaram deste projeto, houve posicionamentos diferentes quanto à abordagem do tema da morte para os residentes. Em uma delas, houve possibilidade de desenvolver o projeto com residentes e profissionais; na outra, o interdito da morte ficou bem nítido, pela recusa de se passar o filme Falando de Morte com o Idoso, porque havia o temor de causar sofrimento adicional aos residentes, e não a possibilidade de abrir espaço para compartilhamento e reflexão.

Os temas levantados nos projetos sobre instituições para idosos envolveram a decisão de se falar ou não sobre a morte para quem está próximo dela. Será que provocaria sofrimentos adicionais? Os idosos deveriam ser poupados? Os profissionais que participaram dos projetos ponderaram que, se idosos não falam sobre a morte, é porque não querem tocar no assunto. Mas, não é justamente para eles que se deveria proporcionar acolhimento abordando o tema da morte? O que se 
apontou em uma das instituições pesquisadas foi que falar sobre a morte sempre causa sofrimento, permanecendo a questão: a quem caberia abordar a questão da morte com os residentes, aos profissionais da instituição ou a alguém externo à entidade?

Para os profissionais de saúde das instituições pesquisadas, refletir sobre o tema da morte é importante na sua vida pessoal e profissional, e afirmam que precisam ser cuidados para cuidar melhor dos idosos.

Sintetizando, poderíamos dizer que, nas instituições asilares, a morte é, em alguns casos, tema interdito na própria instituição, não se tendo espaço para falar sobre o assunto, como se aí não coubesse. Para alguns profissionais, a questão da morte é vista como interdito, porque não sentem que é sua função lidar com o tema; acreditam que a sua abordagem poderia causar mais sofrimento aos idosos e, principalmente, porque não se sentem preparados para realizar essa tarefa. A maioria dos profissionais pensa que abrir espaços de discussão pode ajudálos na tarefa de cuidar dos idosos em todas as esferas, porque poderiam se conhecer e assim compreender o comportamento dos residentes.

É importante propor cuidados aos profissionais que cuidam de pessoas no fim da vida no deserto afetivo que se forma dentro dos hospitais, rever a negação, o silêncio, a ilusão de onipotência. É importante que profissionais de saúde possam perceber que não estão sós, que não precisam afundar nas suas aflições.

Foi objetivo desta pesquisa também avaliar os filmes do projeto Falando de Morte. De maneira geral, os filmes foram apreciados pelos participantes, sendo vistos como instrumentos facilitadores da comunicação sobre a morte, que permitiram a reflexão sobre seus vários aspectos.
O filme Falando de Morte: a Criança recebeu críticas relacionadas ao fato de não se saber qual o público alvo: a criança ou o adulto. O filme é dirigido a pais, educadores e profissionais de saúde, estimulando reflexões sobre como lidar com crianças saudáveis, enlutadas, enfermas e seus familiares, e não tem como objetivo substituir o contato direto com os profissionais na sua atividade de cuidar.

O filme Falando de Morte com Idosos teve as críticas focadas no fato de que suas cenas não abordam a realidade específica do idoso asilado, e que a classe socioeconômica dos idosos do filme não é semelhante à população que vive nas instituições estudadas. Mesmo assim, consideramos que poderia ser oportuno passar o filme para os idosos, abrindo possibilidades de compreensão dos temas abordados para estimular a discussão sobre perdas, morte e comunicação.

O filme Falando de Morte com os Profissionais de Saúde recebeu críticas vinculadas à duração e à repetição de temas.

Muitas sugestões de inclusão foram feitas aos filmes do projeto Falando de Morte, que, oportunamente, poderão ser aproveitadas em caso de reformulação. Por enquanto, as alterações propostas poderão ser alvo de debate após a exibição dos filmes aos grupos a que foram destinados. De maneira geral, os filmes foram recomendados para o preparo de profissionais na abordagem da morte nas instituições de saúde, como facilitadores para abertura, sensibilização e discussão sobre o tema.

As reflexões sobre a questão da morte nas instituições de saúde são ainda bem gerais. Pretendemos, em futuros projetos, estudar a questão mais detalhadamente, incluindo as instituições de educação. 
Em sequência a esse projeto de cunho exploratório, pretendemos, em pesquisas futuras, aprofundar o tema a partir da proposta de realização de atividades de grupo e de sua análise, buscando compreender porque a morte é ainda tema interdito e de difícil comunicação em instituições que abrigam pessoas em situações de perda e de morte, como hospitais e instituições de longa permanência para idosos.

\section{Maria Júlia Kovács}

Professora Associada do Departamento de Psicologia da Aprendizagem, do Desenvolvimento e da Personalidade do Instituto de Psicologia da USP, São Paulo - SP - Brasil.

E-mail:mjkoarag@usp.br

Endereço para envio de correspondência:

Av. Mello Moraes, 1721 - Cidade Universitária. São Paulo, SP - Brasil. CEP: 05.508-030.

Recebido 14/4/2010, 1a Reformulação 1/2/2011, Aprovado 5/5/2011.

Ariès, A. (1977). História da morte no ocidente. Rio de Janeiro: Francisco Alves.

Carvalho, V. A. (2004). Cuidando do cuidador. In L. Pessini, \& L. Bertanchini (Orgs.), Humanização e cuidados paliativos (pp. 309-315) São Paulo: Edições Loyola/São Camilo.

Casellato, G. (Org.). (2005). Dor silenciosa ou dor silenciada? Perdas e lutos não reconhecidos por enlutados e sociedade. Campinas, SP: Livro Pleno.

Doka, K. J. (1981). Recent bereavement and registration for death student courses. Omega, Journal of Death and Dying, 12(1), 51-60.
Durlak, J. A., \& Riesenberg, L. A. (1991). The impact of death education. Death Studies 13, 39-58

Esslinger, I. (2004). De quem é a vida, afinal? Descortinando cenários da morte no hospital. São Paulo: Casa do Psicólogo.

Fonseca, J. P. (2004). Luto antecipatório. Campinas, SP: Livro Pleno.

Franco, M. H. P. (2002). Estudos avançados sobre o luto. Campinas, SP: Livro Pleno.

Franco, M. H. P. (2010). Porque estudar luto na atualidade. In M. H. P. Franco, Formação e rompimento de vínculos: o dilema de perdas na atualidade (pp. 17-42). São Paulo: Summus. 
Glass Jr., J. C. (1990). Changing death anxiety through death education in public schools. Death Studies, 14, 31-52.

Gutierrez, B. A. (2003). O processo de morrer no cotidiano do trabalho dos profissionais de enfermagem de unidades de terapia intensiva. Tese de doutorado. Escola de Enfermagem da Universidade de São Paulo, São Paulo.

Hayslip, B. Galt, C., \& Pinder, M. (1993/1994). Effects of death education on conscious and unconscious death anxiety. Omega, Journal of Death and Dying, 28(2), 101-111.

Hennezel, M. (2001). Nós não nos despedimos. Lisboa: Editorial Notícias.

Johansson, N., \& Div,T. L. D. (1990/1991). Effectiveness of a death education program in reducing death anxiety of nursing sutdents. Omega, Journal of Death and Dying, 22(1), 25-33.

Junqueira, L. C. U. (2008). Vivências de médicos oncologistas: um estudo da religiosidade no cuidado existencial em saúde. Dissertação de mestrado. Universidade de São Paulo, Ribeirão Preto, São Paulo.

Knight, K. H., \& Elfenbein, M. H. (1993). Relationship of death education to the anxiety, fear and meaning associated with death. Death Studies, 17, 411-425.

Kovács, M. J. (1989). A questão da morte e a formação do psicólogo. Tese de doutorado, Instituto de Psicologia da Universidade de São Paulo, São Paulo.

Kovács, M. J. (1992). Morte e desenvolvimento humano. São Paulo: Casa do Psicólogo.

Kovács, M. J. Falando de morte [Filme vídeo]. São Paulo: Instituto de Psicologia da Universidade de São Paulo.

Kovács, M. J. (2003a). Comunicação nos programas de cuidados paliativos. Mundo da Saúde, 27(27), 71-80.

Kovács, M. J. (2003b). Educação para a morte. Desafio na formação de profissionais de saúde e educação. São Paulo: Casa do Psicólogo.

Kovács, M. J. (2003c). Educação para a morte. Temas e reflexões. São Paulo: Casa do Psicólogo.

Kovács, M. J. (2004). Falando de morte com os profissionais de saúde [Filme vídeo]. São Paulo: Insituto de Psicolgia da Universidade de São Paulo.

Kovács, M. J. (2007). Contribuições de Elizabeth Kübler-Ross nos estudos sobre a morte e o morrer. In D. Incontri, \& Santos, F. S. (Orgs.), A arte de morrer. Visões plurais (pp.207-216) São Paulo: Comenius.

Kovács M. J. (2009). Pesquisa com pacientes gravemente enfermos: autonomia, riscos, benefícios e dignidade. Revista Bioética, 17(2), 309-318.

Leviton, D. (1975). Education for death, or death becomes less a stranger. Omega, Journal of Death and Dying, 6(3), 183-191.

Machado, A. G., \& Merlo, A. R. C. (2006). Cuidadores, seus amores e suas dores: o prazer e o sofrimento psíquico dos auxiliares e técnicos de enfermagem de um hospital cardiológico. Psicologia e Sociedade, 20(3), 444-452.

Maglio, C. \& Robinson, S. (1994). The effects of death education on death anxiety. Omega, Journal of Death and Dying, 29(4), 319-335.
Martins, A. (2004). Biopolítica: o poder médico e a autonomia do paciente em uma nova concepção de saúde. Interface Comunicação e Saúde, Educação, 8(14), 21-32.

Mc Farland, K. M. F., Rollim, E. C., Gonzalez, F. M., \& Rhoades, D. R. (1994). Dealing with death and dying. Medical Education, 28, 136-138.

Minayo, M. C. (2000). O desafio do conhecimento. Pesquisa qualitativa em saúde. Rio de Janeiro: Hucitec/Abraso.

Mishara, B. L. (1999). Synthesis of research and evidence on factor affecting the desire of terminally ill or seriously chronically ill persons to hasten death. Omega, Journal of Death and Dying, 39(1), 1-70.

Mota, J. A. C. (1999). Quando um tratamento se torna fútil Bioética, 7(1), 35-40.

Pessini, L. (2004). Humanização da dor e do sofrimento humano na área de saúde. In Pessini, L., \& Bertanchini, L., Humanização e cuidados paliativos (pp.11-30) São Paulo: Loyola/São Camilo.

Quintana, A. M., Kegler, P. S., Maúcha, S., \& Lima, L. D. (2006) Sentimentos e percepções da equipe de saúde frente ao paciente terminal. Paidéia, 16(35), 415-425.

Rezende, V. L. (2000). Os últimos momentos: abordagem psicológica para pacientes terminais. Campinas, SP: Editora da Unicamp.

Schramm, R. F. (2002). A questão da definição da morte, na eutanásia e no suicídio assistido. Mundo da Saúde, 26(1) 178-183.

Schultz, R., \& Schlarb, J. (1987/1988). Two decades of research on dying. What do we know about the patient? Omega, Journal of Death and Dying, 18(4), 299-317.

Schutz, A. (1979). Fenomenologia e relações sociais. Rio de Janeiro: Zahar.

Silva, G. S. N. \& Ayres, J. R. C. M. (2010). Os estudantes de medicina e o encontro com a morte: dilemas e desafios. In M. H. P. Franco (Org.), Formação e rompimento de vínculos: o dilema das perdas na atualidade (pp. 43-72). São Paulo: Summus.

Silva, M. J. P. (2002). O papel da comunicação na humanização da atenção à saúde. Bioética, 10(2), 73-88.

Sousa, D. M., Soares, E. O., Costa, K. M. S., Pacífico, A. L. C. \& Parente, A. C. M. (2009). A vivência da enfermeira no processo de morte e morrer dos pacientes oncológicos. Texto \& Contexto de Enfermagem, 18(1), 41-47.

Spink, M.J. (1999). Práticas discursivas e produção de sentidos no cotidiano. São Paulo: Cortez Editores.

Steytler, M. E. (2007). Vivências de médicos que atuam em oncologia diante da terminalidade: uma análise compreensiva. Dissertação de mestrado. Universidade de São Paulo, Ribeirão Preto, SP

Stillion, J. (1989). Association for death education and counselling: An organization for our times and for our future. Death Studies, 13, 191-201.

Thiollent, M. (1987). Metodologia da pesquisa-ação. São Paulo: Editora Cortez. 